\title{
Fat Tax As An Alternative Tax In South Africa
}

Lizelle Talbot, University of Pretoria, South Africa

Saré Pienaar, University of Pretoria, South Africa

\begin{abstract}
South Africa, like many other countries, is struggling with raising levels of obesity and the resultant health problems. Furthermore, as elsewhere in the world, this country is experiencing an ever-increasing need for additional fiscal revenue. These problems force governments all over the world to investigate possible solutions to these issues. The aim of this study was to determine whether fat tax can be used as a tool to decrease the rising rate of obesity in South Africa and thus improve the general health of South Africans and to create additional tax revenue. Available literature was compared and critically analyzed in terms of South African conditions in order to determine whether fat tax should be considered as an alternative tax in South Africa. Cultural beliefs that see obesity as a sign of good health and prosperity, as well as the extreme poverty experienced by a large proportion of the populace are factors that make it difficult to compare the findings of studies conducted in the rest of the world to those of South African research. These are aspects that should be considered for further research. Fat tax has potential as an alternative tax in order to bring about behavioural change and create revenue; however, this should be done with careful consideration as to whether the benefits outweigh the cost of its implementation for the South African taxpayer.
\end{abstract}

Keywords: Fat Tax; Obesity; Behavioral Change; Additional Tax Revenue

\section{INTRODUCTION}

frica was once the continent associated with under-nutrition. However, a conflicting problem was found when the World Health Organization reported that the number of overweight and obese children and adolescents in Africa doubled from 1990 to 2010 and that South Africa's youth, specifically, finds itself in the position comparable to those of developing countries a decade ago (Rossouw, Grant \& Viljoen, 2012). In 1789, Benjamin Franklin stated that "in this world nothing can be said to be certain, except death and taxes" (Bartleby quotations, 2012). Creighton (2010) revised this statement with regard to the United States of America (USA) to include obesity as another certainty. In several parts of the world, taxation has been imposed by governments in an attempt to solve this problem. Van der Merwe and Pepper (2006) point out that the World Health Organization has recognized obesity as a chronic disease. Seiders and Petty (2004) states that obesity causes as many deaths in the USA as smoking.

The first so-called 'sin tax' was imposed in Pennsylvania USA by Alexander Hamilton in 1791 (Altman, 2009), not only to increase state revenue, but also to decrease the consumption of harmful consumer goods (Green, 2010). To a certain extent sin taxes are meant to alter the behaviour of taxpayers, especially the poor who cannot afford to be spending on sin goods (Caraher \& Cowburn, 2005. Today, the imposition of sin taxes tends to be construed, often quite correctly, as a tax on behaviour and used by governments as a tool to encourage self-control instead of as a mere source of revenue creation (Green, 2010).

The latest sin tax that has been debated and in some cases implemented in countries around the world is the controversial 'fat tax' (Hunter, 2004). There are many differing expressions that refer to this type of excise duty. McColl (2009) refers to it as 'fat tax'; 'junk food taxes' or 'soda tax'; Kuchler, Tegene, and Harris (2005) call this type of tax a 'snack tax', while Sheu (2006) notes that the tax is sometimes referred to as a 'Twinkie tax' or a 
'selective food tax'. In essence, all these terms imply that an excise duty or a sin tax on high fat, high sugar foods is imposed. The imposition of the first recorded true fat tax was only announced on 1 October 2011, according to Mike Rayner, the Director of Oxford University's Health Promotion Research Group (Molland, 2011). This groundbreaking tax, which is based on the amount of saturated fat in foods, was introduced in Denmark (Best, 2011).

Available literature reveals that the underlying objectives of sin taxes and more specifically fat tax are divided between whether these objectives are intended to alter consumer behaviour or to generate additional revenue. Caraher and Cowburn (2007) are of the opinion that sin taxes are tools used to alter the behaviour of taxpayers, whereas Sanson (2005) comments that sin taxes are often used merely to increase governments' tax revenues.

In South Africa very little research on the behavioural effects of sin taxes has been done. In view of the proposed implementation of National Health Insurance scheme in South Africa in 2012/2013 (South African Government Information, 2012), the research investigated whether fat tax should be considered as the revenue creation potential of these taxes in South Africa as well as an alternative tax in an attempt to change behaviour. To achieve these aims, a comprehensive literature review, utilizing comparative analysis of literature is presented. The article closes with conclusions and recommendations.

\section{LITERATURE REVIEW}

People tend to believe no one should interfere with the choices they make regarding risks to their own personal health, but that such choices should be made at their own discretion. This view is termed "consumer sovereignty". In strict contrast to the notion of consumer sovereignty the idea that a government enforces control through sin taxes is referred to as "paternalism" (Strnad, 2004). The notion of paternalism refers to the policies designed by those in power, such as the government, to alter the behaviour of the people who are subject to them into making choices that they (the authorities) believe to be more preferable (O'Donoghue \& Rabin, 2006). Many people regard this form of government intervention as a direct attempt to control what the people may or may not consume, leaving them with the impression that they live in a "nanny state" (Brownell \& Warner, 2009).

Rising obesity rates have highlighted the need for a tax on high fat, high sugar content foods as statistics show that addiction to food and obesity in general may cause more deaths than cigarette smoking ([The] elephant in the room, 2003). It is important to determine whether the underlying objectives of sin taxes and more specifically fat tax have been reached and whether these objectives were intended to alter consumer behaviour or merely to generate additional revenue or both.

\section{METHODOLOGY}

This literature study was done in the form of a comparative study of available literature. A search of recent literature from 1990 to the present was performed. The databases searched were ProQuest, EbscoHost, Emerald and Sabinet, which enabled searches in many different journals. The search terms used were "sin tax", "fat tax", "soda tax", "snack tax", "obesity", "body mass index" and "BMI" in combination with the terms tax and taxation. In addition, Google Scholar was used to identify authors with a high citation. The literature that was reviewed may not be all inclusive, but it provided a platform from which to evaluate the potential use of a fat tax in a South African context.

\section{THE EFFECT OF TAXES ON BEHAVIOURAL CHANGE AND DECISION MAKING}

The best examples of paternalism currently enforced by many governments, including South Africa, are the sin taxes on tobacco and alcohol. Both internationally and in South Africa, research has proved that sin taxes on tobacco and alcohol could be effective to decrease consumption. Cigarettes and alcohol are universally acknowledged as being addictive. Modern sin taxes tend to be targeted at goods which are known to be addictive and therefore, these taxes may assist people in controlling their addictions (Chaloupka \& Warner, 1999; Van Walbeek, 2003). 
Green (2010) claims that the consumption of highly refined carbohydrates may cause addictions, such as, tobacco and alcohol. A study found that obese persons' brain responses to food were very similar to the response of a known cocaine addict's brain when a dose of the drug is administered (Richards, Patterson \& Tegene, 2007). According to this study, it was found that it was not specific foods that were found to be addictive, but rather certain components and the chemistry of these components, such as sugars or fats.

Obesity is very often the end result of food addiction and much of the literature on fat taxes indicates that obesity is the main contributing factor to many diseases associated with eating patterns, such as hypertension, heart disease and other diseases (Cawley, 2006).

Fletcher, Frisvold and Tefft (2010) did a study in the USA on the effectiveness of a fat tax on the population's weight control by comparing the effects of the institution of a fat tax on the overall body mass index (BMI) of the population. BMI is a unit of measurement used in order to determine healthy body weight (Gelbach, Klick, \& Stratmann, 2007). It was found that a fat tax on soft drinks would have an impact on the weight of individuals. The scale of the impact would, however, be relatively small due to the current low rates at which these taxes are imposed. The study suggests that there would be a definite decrease in the overall BMI of the population since it was found that a $1 \%$ fat tax would decrease BMI by approximately 0.003 points.

The effect of a fat tax on lower income groups is greater. Fletcher et al.'s (2010) research shows that a 1\% fat tax can decrease obesity by $0.08 \%$ and overweight by $0.1 \%$ in the case of lower income groups. Higher income groups are affected to a smaller degree: a decrease of only $0.05 \%$ was shown in obesity and a $0.08 \%$ decrease in overweight. The research further speculates that increase equal to the sin tax on cigarettes will decrease obesity by $0.7 \%$.

Seiders and Petty (2004) have pointed out that obesity causes as many deaths as smoking in the USA. Obesity rates are climbing in South Africa and it might be time to ask why the South African government does not impose a tax on certain foods which, when over-consumed, could lead to obesity. South Africa's Minister of Health, Dr Aaron Motsoaledi, has emphasized the need for South Africans to adopt healthier lifestyles (Get healthy, urges Motsoaledi 2011). This is clear evidence that South Africa is serious about the need for behavioural change in terms of health and obesity. The minister stated that South Africans need to pursue healthier life styles through exercise, healthy eating and avoiding tobacco. He also indicated that this may decrease the prevalence of diabetes and hypertension in the population.

A South African study on obesity found that there were exceptional differences in the rates of overweight and obesity amongst different racial groups (Van der Merwe \& Pepper, 2006) A BMI of more than 25 is considered to be overweight in the results (see Figure 1).

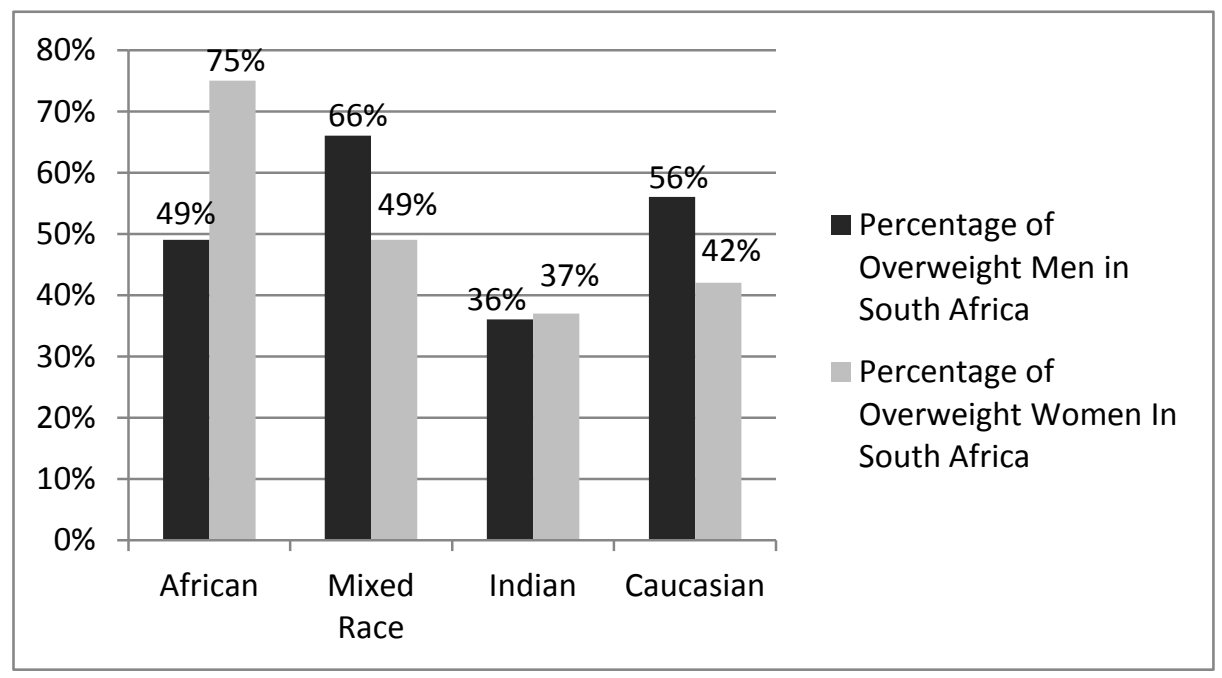

Figure 1: Statistics of overweight persons in South Africa by ethnic groups Source: Adapted from Van der Merwe and Pepper (2006). 
Of the $75 \%$ African women considered to be overweight, $42 \%$ were found to be obese (having a BMI of more than 30). In general, in the Western world, it is considered a personal failure if you are overweight or obese (Seiders \& Petty, 2004). In a South African context that view is contradicted, since in particular ethnic groups it is part of the culture to seek to be obese. A staggering 15\% of obese black South African women rated themselves as 'underweight' in a survey while almost none of the white women who participated in the study considered themselves to be underweight. Obesity in South Africa is, therefore, also a matter of perception and culture (Bateman, 2007), as confirmed by findings from a study by Malhotra et al. (2008). Bateman's (2007) survey also found that obesity is partly sought after in African culture not only for the social significance, but also because it is assumed that obesity signals an HIV negative status. As demonstrated by the data set out in Figure 1, African women are statistically the most overweight group by far and the myth of benign obesity is the most prevalent amongst them.

Fat taxes were generally seen as an effective behaviour-changing tool in countries which have instituted them. South Africa is beginning to face similar challenges to those in the USA with regard to obesity and its related diseases and, therefore, a fat tax in South Africa may be a worthwhile tool in order to bring down obesity rates in the country. Cultural differences peculiar to South Africa may, however, affect the efficacy of a fat tax in terms of behaviour and choices.

\section{THE POTENTIAL OF FAT TAXES FOR REVENUE CREATION IN SOUTH AFRICA}

The first sin tax which could be considered to be a fat tax was instituted on sugary soda drinks and was introduced in the USA during the First World War. This original fat tax was not brought in as a behavior changing sin tax, but was intended to help fund the First World War. Fat taxes were subsequently used to help absorb some of the costs resulting from the Great Depression in the early 1930s. Fat taxes have been utilized by governments in the past 100 years mainly for revenue-creation purposes whenever the need for additional revenue arose (Sheu, 2006).

Economic decline has become a global phenomenon. The recent recession which first emerged in the USA in the latter half of 2007 has created the need for further revenue-generating tools for governments around the world. The current recession has been compared to the Great Depression and, just as in that era, governments are now searching for revenue-generating tools while trying to avoid increases in income tax and other general taxes (Smith, 2009).

The revenue-creating potential of fat taxes has proved that fat taxes are not to be dismissed as a purely behavior changing solution and currently, just as in the past; some governments institute a fat tax simply to cover their shortfall. In 2005, the mayor of Detroit wanted to introduce a $2 \%$ tax on fast foods to generate millions of dollars to help with the budgetary shortfall (Sanson, 2005).

In 2000, 19 American states had already instituted minor taxes mostly on carbonated drinks, sweets or snack foods (Jacobson \& Brownell, 2000). In that year they generated over a billion dollars in tax revenue. Of the 19 states mentioned above, 14 states used this money to supplement the total income of government. The remaining states earmarked the revenue for specific purposes, such as assisting medical educational institutions, environmental concerns and refuse control, and violence and drug control. Only Arkansas earmarked the funds for its public medical scheme (Jacobson \& Brownell, 2000).

Where a government is merely trying to magnify its tax revenues and, therefore, not expressly attempting to alter the behaviour of taxpayers, the fat taxes instituted may be so small that consumers may hardly notice that they exist and, yet, it may still be an effective revenue-creating tool (Sanson, 2005).

State governments in the USA have instituted a wide range of fat taxes that differ from state to state. These fat taxes are for the most part used simply as revenue-generating tools and are not meant to alter behaviour. They are mostly taxes that are levied based on the class of the food instead of what the food contains, for example taxes on snack foods or taxes on soft drinks. The imposition of many of these taxes proved that the demand for snack foods is affected by small increases in price. For example, it was found that the demand for certain snack foods dropped by approximately $10 \%$ after a tax was imposed on this class of food (Caraher \& Cowburn, 2005). Therefore, the 
question as to whether a tax that was introduced to generate revenue would not potentially affect consumption so dramatically that no revenue is generated must be considered.

Brownell et al. (2009) claim that if a fat tax of one cent were to be levied on every 30 milliliters of sugarsweetened cold drink in the USA, it would raise an estimated 14.9 billion dollars in revenues annually.

It is clear from the revenue numbers discussed by Brownell et al. (2009) that fat taxes have already been, and can potentially be, an impressive revenue source in the USA.

Although South Africa is far removed from the USA, Europe and other countries hard hit by the recession, the country has not been able to elude the economic downturn and just like many nations globally it finds itself in a fiscal deficit position. The statement regarding the national debt by the South African Minister of Finance, Pravin Gordhan, in the 2012 Budget Speech was reiterated by Maswanganyi (2011) who pointed out that the South African fiscal deficit is expected to increase from $4.6 \%$ to approximately $5.3 \%$ of the gross domestic product for t2012. This deficit can be translated into R142.4 billion for the 2012 fiscal period.

The new proposed National Health Insurance scheme which is to be introduced in South Africa will cost the South African government an estimated R125 billion in 2012, thus creating a further need for South African tax revenues (NHI to cost R125bn by next year, 2011).

Frye (2009) argues that South Africa was already in an economic crisis long before the global economic downturn. Previously, unemployment was excessively high but currently the economic downturn has just magnified the situation. He further states that 22.5 million people were already living in poverty before the economic downturn.

South Africa has world-class metropolitan cities and it is often compared to First World countries as a global player (Frye, 2009). Fakir (2009) mentions that there are many problematic differences between South Africa and other developed nations. Firstly, 60\% of South Africans live in poverty (Blignaut \& Van der Elst, 2009). The South African poverty statistics are significantly higher than in developed nations. Secondly, there tends to be an extreme expectation and dependence upon government to fulfil people's basic needs unilaterally without any recompense (Fakir, 2009).

This attitude of dependence on government for the fulfillment of basic needs highlighted above significantly increases the financial strain on the South African government. Nearly two thirds of South Africans live in desperate poverty and often live off government handouts with no foreseeable possibility of employment (Blignaut \& Van der Elst, 2009). Assubuji and Luckscheiter (2009) state that those who live in poverty are the ones who are worst affected by the economic downturn.

It is unclear whether this attitude of dependence on and expectation of government in South Africa is a cultural problem or learned behaviour, but it may be due to the way in which politicians have enticed voters through promises of free homes, water and electricity, and consequently it could be a government-produced problem. Politicians may have created an absolutely unrealistic expectation through political campaigning, even more so now that the country finds itself in the midst of a recession (Fakir, 2009).

Fakir (2009) states that in 2009, more than 13 million people in South Africa were receiving some form of government grant depleting the tax revenue coffers by approximately R118 billion a year. He points out that it is estimated that these annual grants will climb dramatically and may cost the government R140 billion per annum by the end of 2012. With rising unemployment this figure may continue to rise.

In 2009, South Africa's unemployment rates were hovering close to $30 \%$ and rapidly rising (Fakir, 2009). Unemployment elicits concern about the possible regressive nature of a fat tax, where poor people were to be expending a much larger proportion of their income on the fat tax than the rich (Cawley, 2006). The possibility of how a fat tax may prove to be regressive in nature is illustrated by Shabodien (2009) who confirms that South African underprivileged families expend nearly two thirds, on average, of their income on food. On the other hand, South African food expenditure for middle-class to wealthy families ranges from $24 \%$ to $28 \%$ of their income. 
With reference to soda taxes, Leonhardt (2009) contests Cawley's (2006) findings. According to Leonhardt, it has been found that people, and in particular poorer people, tend to be responsive to price and any increase in price by the institution of a fat tax would more than likely reduce consumption by the poor.

Cawley (2006) contends that arranging foods and categorizing which foods to tax may turn out to be problematic, as it may be difficult who will determine which specific foods lead to obesity. It appears that many countries have opted for a complex system of levying fat tax. The intention behind the institution of the tax is a crucial deciding factor in how the tax should be levied. However, if the costs of the institution of the tax outweigh its benefits, then there may be no point in pursuing it (Caraher \& Cowburn, 2005).

Although there may be significant information to support the institution of a fat tax for revenue generation or behavioural change, the categorization of foods to be taxed might turn out to be very difficult. The possible regressive effects of a fat tax could also prove to be a problem because of the high poverty rates in South Africa.

\section{CONCLUSION}

The recent remarks made by the South African Minister of Health regarding the need for behavioural change to improve the health of South Africans highlights the fact that there is a need for change and that the South African government is starting to take note of this need. An attempt was made in this article to explore whether fat tax should be considered in South Africa as an alternative to create revenue and to change behaviour.

The South African statistics regarding overweight and obesity is evidence that obesity is beginning to run rampant in South Africa in the same way it has in the USA. The belief in certain cultures that obesity is a sign of health, prosperity, affluence and an indication of an HIV-negative status demonstrates that even if measures are put in place to decrease obesity in South Africa, they may be unsuccessful if cultures are distorting people's perceptions of obesity.

As in the case of the efficacy of cigarette and alcohol taxation, fat taxes have been proved to decrease consumption in other countries. It may, however, be debatable if the changes in BMI can be considered to be significant. Cultural beliefs of healthy obesity, coupled with the high rate of unemployment and the extreme poverty experienced by many South Africans make it difficult to compare the findings of studies conducted in South Africa to the outcomes of studies undertaken in the rest of the world. Therefore, thorough additional research needs to be done in order to determine the possible effect of using fat tax to change behaviour.

Due to the current fiscal deficit experienced in South Africa, together with the additional needs created by rising unemployment and the eventual institution of the National Health Insurance scheme, it can be said that there is a substantial reason for instituting some form of fat tax to generate revenue in South Africa. In view of the high rate of unemployment and the extreme poverty experienced in South Africa, the possible regressive nature of a fat tax should be taken into account. Even if it is found that a fat tax would not be significantly regressive, the way in which the relevant industries in South Africa may be affected by the possible institution of a fat tax needs to be considered.

A future quantitative study based on the receptivity of South Africans to a fat tax would be useful for government decision-making. Should South Africa intend instituting a fat tax, it may be a good approach for the government to work in collaboration with the industries which may be affected in order to plan the proposed fat tax.

It appears from the conclusions that have been drawn from this study of the subject literature that a fat tax could be considered as a means of behavioural change and revenue creation, and that its implementation could be substantiated by the current South African economic climate. As such, it may be appropriate for the South African government to consider a fat tax that will help to keep the bread basket full while emptying of undesirable foods leading to unhealthy citizens. 


\section{AUTHOR INFORMATION}

Lizelle Talbot, M Com student in the Department of Taxation at the University of Pretoria, South Africa.

Saré Pienaar, senior lecturer in the Department of Taxation at the University of Pretoria, South Africa. Currently involved in various research projects in tax, focusing on human behavior regarding taxation as well as the applicability of tax policy in terms of the internet transactions. E-mail: sare.pienaar@up.ac.za (Corresponding author)

\section{REFERENCES}

1. $\quad$ Altman, A. (2009). A brief history of: sin taxes. Time Magazine, Thursday 2 April.

2. $\quad$ Assubuji, P. \& Luckscheiter, J. (2009). The global economic crisis and South Africa. Perspectives: political analysis and commentary from Southern Africa, 3(9)1-2.

3. Bartleby quotations, (2012). Bejamin Franklin: Letter to M. Leroy, 1789. Retrieved from: http://www.bartleby.com/100/245.24.html

4. Bateman, C. (2007). Black women at major risk for obesity-related diseases. South African Medical Journal, 97(7):490.

5. Best, D. (2011). Danish fat tax gives industry plenty to chew over. Available at: http://www.justfood.com/comment/danish-fat-tax-gives-industry-plenty-to-chew-over id116864.aspx

6. Blignaut, J.N. \& Van der Elst, L. (2009). South Africa and sustainable development: a reflection. Perspectives, 3(9):13-18.

7. Brownell, K.D., Farley, T., Willett, W.C., Popkin, B.M., Chaloupka, F.J., Thompson, J.W. \& Ludwig, D.S. (2009). The public health and economic benefits of taxing sugar-sweetened beverages. New England Journal of Medicine, 361(16):1599-1605.

8. Brownell, K.D. \& Warner, K.E. (2009). The perils of ignoring history: big tobacco played dirty and millions died. How similar is big food? Milbank Quarterly, 87(1):259-294.

9. Caraher, M. \& Cowburn, G. (2005). Taxing food: implications for public health nutrition. Public Health and Nutrition, 8(8):1242-1249.

10. Cawley, J. (2006). Markets and childhood obesity policy. The Future of Children, 16(1):69-88.

11. Chaloupka, F.J. \& Warner, K.E. (1999). The economics of smoking. Cambridge, MA: National.

12. Creighton, R., (2010). Fat taxes the age old manifestation of the age old excise tax. Journal of Legal Medicine, 31(1):123-136.

13. Elephant in the room: evolution, behavioralism, and counter-advertising in the coming war against obesity [The]. (2003). Harvard Law Review, 116(4):1161-1184.

14. Fakir, S. (2009). Caught between a rock and a hard place: the state of play for South Africa's beleaguered development state. Perspectives, 3(9):3-7.

15. Fletcher, J.M., Frisvold, D. \& Tefft, N. (2010). Can soft drink taxes reduce population weight? Contemporary Economic Policy, 28(1):23-35.

16. Frye, I. (2009). Responses and alternatives: South Africa's response to the crisis. Perspectives, 3(9)8-12.

17. Gelbach, J.B., Klick, J. \& Stratmann, T. (2007). Cheap donuts and expensive broccoli: the effect of relative prices on obesity. Tallahassee: Florida State University. (FSU College of Law, Public Law Research Paper, No. 261):1-52.

18. Get healthy, urges Motsoaledi: press statement. (2011). News24, Wednesday, 7 September. Retrieved from: http://www.news24.com/SouthAfrica/Politics/Get-healthy-urges-Motsoaledi-20110907\#

19. Green, R. (2010). The ethics of sin taxes. Public Health Nursing, 28(1):68-77.

20. Hunter, P.J., (2004). Fat tax, a recipe for a healthy population? Scientist, 18(15):68.

21. Jacobson, M.F. \& Brownell, K.D. (2000). Small taxes on soft drinks and snack foods to promote health. American Journal of Public Health, 90(6):854.

22. Kuchler, F., Tegene, A. \& Harris, J.M. (2005). Taxing snack foods: manipulating diet quality or financing information programs? Review of Agricultural Economics, 27(1):4-20.

23. Leonhardt, D. (2009). Sodas a tempting tax target. The New York Times, 20 May. Retrieved from: http://www.nytimes.com/2009/05/20/business/economy/20leonhardt.html?scp=4\&sq=20\%20May\%202009 \&st $=$ cse

(C) 2012 The Clute Institute http://www.cluteinstitute.com/ 
24. Malhotra, R., Hoyo, C., Ostbye, T., Hughes, G., Schwartz, D., Tsolekile, L., Zulu, J. \& Puoane, T. (2008). Determinants of obesity in an urban township of South Africa. South African Journal for Clinical Nutrition, 21(4):315-320.

25. Maswanganyi, N. (2011). Budget deficit at 5.3\% in 2010, 2011. Available at: http://www.businesslive.co.za/incoming/2011/02/23/budget-deficit-at-5.3-in-2010-2011

26. McColl, K. (2009). "Fat taxes" and the financial crisis. The Lancet, 373:797-798.

27. Molland, J. (2011). A fat tax in Denmark: should it happen in the U.S.? Retrieved from: http://www.care2.com/causes/a-fat-tax-in-denmark-should-it-happen-in-the-us.html

28. NHI to cost R125bn by next year. (2011). Fin24 Economy. 11 August. Retrieved from: http://www.fin24.com/Economy/NHI-to-cost-R125bn-by-next-year-20110811

29. O'Donoghue, T. \& Rabin, M. (2006). Optimal sin taxes. Journal of Public Economics, 90(10-11):18251849.

30. Richards, T.J., Patterson, P.M. \& Tegene, A. (2007). Obesity and nutrient consumption: a rational addiction? Contemporary Economic Policy, 25(3):309-324.

31. Rossouw, H.A., Grant, C.C. \& Viljoen, M. (2012) Overweight and obesity in children and adolescents: The South African problem. The South African Journal of Science, 108(5/6):1-7.

32. Sanson, M. (2005). “Another tax on food? Enough is enough!” Restaurant Hospitality, 89(6):10.

33. Seiders, K. \& Petty, R.D. (2004). Obesity and the role of food marketing: a policy analysis of issues and remedies. Journal of Public Policy \& Marketing, 23(2):153-169.

34. Shabodien. (2009). The impacts of global economic crisis on women farm workers in South Africa. Perspectives, 3(9):19-22.

35. Sheu, W. (2006). The evolution of the modern snack tax bill: from World War I to the war against obesity; paper submitted in satisfaction of the Food and Drug Law course requirement. Harvard Law School. (Unpublished).

36. Smith, K.W. (2009). The effect of the global economic crisis on state and local tax revenues. UNC School of Government Economics Bulletin, 3(3 August):1-7. Available at: http://sogpubs.unc.edu/electronicversions/pdfs/eb3.pdf

37. South African Government Information. (2012). 2012 budget speech by Minister of Finance, Pravin Gordhan: press statement issued on 22 February 2012.

38. Strnad, J.F. (2004). Conceptualizing the 'fat tax': the role of food taxes in developed economies. Southern California Law Review, 78:1221-1326.

39. Van der Merwe, M.T. \& Pepper, M.S. (2006). Obesity in South Africa. Obesity Reviews, 7(4):315-322.

40. Van Walbeek C. (2003). Tobacco excise taxation in South Africa. Retrieved from: http://www.who.int/tobacco/training/success_stories/en/best_practices_south_africa_taxation.pdf 